\title{
Retinoids cause apoptosis in pancreatic cancer cells via activation of RAR- $\gamma$ and altered expression of $\mathrm{Bcl}-2 / \mathrm{Bax}$
}

\author{
F Pettersson', AG Dalgleish', RP Bissonnette ${ }^{2}$ and KW Colston*,1 \\ 'Department of Oncology, Gastroenterology, Endocrinology and Metabolism, St George's Hospital Medical School, London SWI7 ORE, UK; '2Ligand \\ Pharmaceuticals Inc., San Diego, California, CA 92121, USA
}

\begin{abstract}
All-trans-retinoic acid and 9-cis-retinoic acid have been reported to have inhibitory effects on pancreatic adenocarcinoma cells and we have shown that this is partly due to induction of apoptosis. In this study, the mechanisms whereby 9-cis-retinoic acid induces apoptosis in these cells were investigated. An involvement of the Bcl-2 family of proteins was shown, such that 9-cisretinoic acid causes a decrease in the $\mathrm{BCl}-2 / \mathrm{Bax}$ ratio. Overexpression of $\mathrm{Bcl}-2$ also resulted in inhibition of apoptosis induced by 9-cis-retinoic acid. Furthermore, two broad-range caspase inhibitors blocked DNA fragmentation induced by 9-cis-retinoic acid, but had no effect on viability defined by mitochondrial activity. Using synthetic retinoids, which bind selectively to specific retinoic acid receptor subtypes, we further established that activation of retinoic acid receptor- $\gamma$ is essential for induction of apoptosis. Only pan-retinoic acid receptor and retinoic acid receptor- $\gamma$ selective agonists reduced viability and a cell line expressing very low levels of retinoic acid receptor- $\gamma$ is resistant to the effects of 9-cis-retinoic acid. A retinoic acid receptor- $\beta$ / $\gamma$ selective antagonist also suppressed the cytotoxic effects of 9-cis-retinoic acid in a dose-dependent manner. This study provides important insight into the mechanisms involved in suppression of pancreatic tumour cell growth by retinoids. Our results encourage further work evaluating the clinical use of receptor subtype selective retinoids in pancreatic carcinoma. British Journal of Cancer (2002) 87, 555 -56I. doi:I0.I038/sj.bjc.6600496 www.bjcancer.com
\end{abstract}

(c) 2002 Cancer Research UK

Keywords: pancreatic cancer; retinoids; apoptosis; Bcl-2

Despite a lot of effort put into improving diagnosis, staging and treatment of pancreatic cancer during the past decades, it is still one of the leading causes of cancer-related deaths in the western world. Fiveyear survival is less than $5 \%$ and the median survival time for patients diagnosed with advanced disease is about 5 months (Rosewicz and Wiedenmann, 1997; Harris and Bruckner, 2001). Surgery is the only curative treatment for pancreatic cancer but a very small percentage of tumours are actually resectable, due mainly to the fact that most patients present late with locally advanced or metastatic disease. Even after surgery, 5-year survival rates reported from most institutions are only around 10\% (Rios et al, 1999; Wagner et al, 1999) and as a consequence, adjuvant and neoadjuvant treatments are important issues. Current chemotherapeutic strategies are generally ineffective (van Riel et al, 1999).

Retinoids are natural or synthetic derivatives of vitamin A. The physiological form of vitamin A is retinol, which is metabolised in its target cells to retinal and then further oxidised to form all-transretinoic acid (ATRA) and its stereoisomer 9-cis-retinoic acid (9cRA) (Vieira et al, 1995). In the late sixties, vitamin A was shown to have anti-tumour activity (Saffiotti et al, 1967) and it has since been shown that retinoic acids and other retinoid-related compounds cause growth inhibition, accompanied by induction of differentiation and/or apoptosis, in various types of cancer cells (Bollag et al, 1994; De Luca et al, 1995; Lippman et al, 1995). Retinoids exert their effects by interacting with nuclear receptors functioning as ligand-dependent transcription factors that switch a variety of genes on and off (Evans, 1988). There are two families of receptors binding retinoic

*Correspondence: KW Colston; E-mail: kcolston@sghms.ac.uk Received 21 March 2002; revised 28 May 2002; accepted 31 May 2002 acids, the retinoic acid receptors (RARs) and the retinoid $\mathrm{X}$ receptors (RXRs). Each family has three subtypes $(\alpha, \beta$ and $\gamma)$ and each of those a number of isoforms. The natural ligand for RARs is ATRA whereas 9cRA binds to both RARs and RXRs with high affinity (Heyman et al, 1992). The activity of RARs and RXRs is further regulated by the presence of numerous coregulatory molecules, which act at least in part through regulation of histone acetylation and modulation of chromatin structure (for review see Freedman, 1999; Glass and Rosenfeld, 2000).

Responsiveness to retinoids in pancreatic cancer cells has previously been reported by different groups (Rosewicz et al, 1995; Bold et al, 1996; Louvet et al, 1996). A phase II trial of 13-cis retinoic acid and interferon- $\alpha$ in patients with advanced pancreatic carcinoma has also been completed and promising results with one partial remission and 14 out of 22 patients with stable disease for a median duration of 5 months were reported (Brembeck et al, 1998). We have shown that ATRA and 9cRA induce apoptosis in a number of pancreatic adenocarcinoma cell lines and enhance the cytotoxic effects of chemotherapeutic agents in these cells (Pettersson et al, $2000,2001)$. In the present study, we examined the role of two families of proteins that are important players in many apoptotic responses, the Bcl-2 proteins and caspases. Furthermore, the involvement of different RAR and RXR subtypes in this response was investigated and a critical role for RAR-gamma was identified.

\section{MATERIALS AND METHODS}

\section{Cell lines}

The human pancreatic adenocarcinoma cell line T3M-4 was obtained from Professor N Lemoine (ICRF, UK). All other cells 
Table I Receptor selectivity and binding constants $\left(K_{i}\right)$ of retinoids used in the study

\begin{tabular}{|c|c|c|c|c|c|c|}
\hline \multirow[b]{2}{*}{ Retinoid } & \multicolumn{2}{|c|}{ Compound profile } & \multicolumn{4}{|c|}{ Receptor binding $\left(K_{\mathrm{i}}, \mathrm{nM}\right)$} \\
\hline & Selectivity & Activity & $\mathbf{R A R} \alpha$ & $\mathbf{R A R} \beta$ & $\mathbf{R A R} \gamma$ & $\mathbf{R} \mathbf{X} \mathbf{R} \alpha$ \\
\hline LG 101305 & $R \times R-\alpha / \beta / \gamma$ & Agonist & $10000^{\mathrm{a}}$ & $10000^{\mathrm{a}}$ & $10000^{\mathrm{a}}$ & 4 \\
\hline LG 030593 & RAR- $\alpha$ & Agonist & 7 & |428| & $20054^{\mathrm{a}}$ & 5000 \\
\hline LG 101093 & RAR $-\gamma$ & Agonist & $10000^{\mathrm{a}}$ & $10000^{\mathrm{a}}$ & 531 & 5365 \\
\hline LGD 1550 & RAR- $\alpha / \beta / \gamma$ & Agonist & 1.1 & 0.7 & 1.9 & 224 \\
\hline LG 030403 & RAR $-\beta / \gamma$ & Antagonist & 5800 & 112 & 125 & 8333 \\
\hline \multirow[t]{2}{*}{$9 c R A$} & $\mathrm{RAR}-\alpha / \beta / \gamma$ & Agonist & 9.3 & 97 & 148 & 8 \\
\hline & $\mathrm{R} \times \mathrm{R}-\alpha / \beta / \gamma$ & & & & & \\
\hline
\end{tabular}

${ }^{\mathrm{a}}>10000 \mathrm{nM}$

were obtained from the American Tissue Culture Collection. Cells were maintained in RPMI-1640 culture medium with $10 \%$ foetal calf serum (FCS), $2 \mathrm{mM}$ L-glutamine and antibiotics at $37^{\circ} \mathrm{C}$ in a humidified atmosphere containing $5 \% \mathrm{CO}_{2}$. During all experiments, cells were grown in medium containing $2.5 \%$ FCS. Under these conditions, the level of endogenous retinoic acid in the medium is less than $10^{-9} \mathrm{M}$, which is negligible (Napoli, 1996). Cells were routinely tested for mycoplasma contamination.

\section{Reagents}

ATRA and 9cRA were purchased from SIGMA (Poole, UK). Receptor subtype-selective analogues were provided by Ligand Pharmaceuticals Inc. (San Diego, CA, USA) The compounds were characterised for their receptor subtype selectivity as previously described (Allegretto et al, 1993) (see Table 1). The pUSEamp $(+)$ plasmid containing wild-type mouse Bcl-2 under the control of the cytomegalovirus (CMV) promoter was obtained from Upstate Biotechnology (Lake Placid, NY, USA). A control vector without insert was supplied by the same source. The broad range caspase inhibitors Z-VAD.fmk (Z-Val-Ala-Asp $(\mathrm{OMe})-\mathrm{CH}_{2} \mathrm{~F}$ ) and BocD.fmk (Boc-Asp $(\mathrm{OMe})-\mathrm{CH}_{2} \mathrm{~F}$ ) were purchased from Calbiochem (Nottingham, UK). The peptides were dissolved in DMSO and stock solutions kept at $-20^{\circ} \mathrm{C}$. Antibodies for RAR- $\alpha, \beta, \gamma$, RXR- $\alpha$ and Bax were purchased from Santa Cruz Biotechnology, Inc. (Santa Cruz, CA, USA). A Bcl-2 specific antibody was obtained from Dako (High Wycombe, UK).

\section{Viability assay}

Assessment of relative numbers of viable cells was done using an MTT tetrazolium assay (Mosmann, 1983). Cells were cultured in 96-well plates in $200 \mu \mathrm{l}$ of medium containing $2.5 \%$ serum and the inhibitory compounds. At each time point, $20 \mu \mathrm{l} 3-(4,5-$ dimethylthiazol-2-yl)-2,5-diphenyltetrazolium bromide (MTT) ( $5 \mathrm{mg} \mathrm{ml}^{-1}$, SIGMA) was added to each well and the plates were incubated at $37^{\circ} \mathrm{C}$ for $4 \mathrm{~h}$. The medium was then removed and formazan crystals were dissolved in $100 \mu \mathrm{l}$ of acidic isopropanol $(0.05 \mathrm{M} \mathrm{HCl})$. Optical density was measured at $550 \mathrm{~nm}$.

\section{Apoptosis assays}

Propidium iodide (PI) staining followed by flow cytometric analysis was used to detect cells with a sub-G1 DNA content. After treatment, cells were harvested by trypsinisation, washed twice with sample buffer (PBS+1 g $1^{-1}$ glucose) and fixed in $70 \%$ ethanol at a density of $1 \times 10^{6}$ cells $/ \mathrm{ml}$. After $\geqslant 18 \mathrm{~h}$ cells were washed with sample buffer and resuspended in PI staining solution containing $50 \mu \mathrm{g} \mathrm{ml}^{-1}$ PI and $20 \mu \mathrm{g} \mathrm{ml}^{-1}$ RNase A. Fluorescence was measured on a Becton-Dickinson FACScan and DNA histograms were analysed using ModFitLT software. Apoptosis was also assessed using the Boeringer-Mannheim Cell Death Detection ELISA $^{\text {PLUS }}$ kit, which detects the presence of histone-associated DNA fragments in the cell cytosol, according to the manual supplied by the manufacturer. Apoptotic index $=\mathrm{OD}_{\text {(treated cells) }} /$

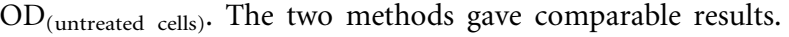

\section{Stable transfections}

T3M-4 cells were transfected with the pUSEamp.Bcl-2 plasmid or a control plasmid without insert, using SuperFect ${ }^{\mathrm{TM}}$ transfection reagent (Qiagen Ltd., West Sussex, UK), according to the manufacturer's instructions. Selection of transfected clones was done using culture medium containing $0.6 \mathrm{mg} \mathrm{ml}^{-1} \mathrm{G} 418$ sulphate (Geneticin ${ }^{\mathrm{B}}$, Life Technologies, Paisley, UK). Expression of Bcl-2 was assessed by Western blotting in selected clones using an antibody supplied by Upstate Biotechnology (Lake Placid, NY, USA).

\section{Western blotting}

Cells were harvested by scraping and whole cell lysates were prepared by washing the cells in ice cold PBS and resuspending them in lysis buffer ( $50 \mathrm{~mm}$ Trizma, $\mathrm{pH} 8.0,150 \mathrm{mM} \mathrm{NaCl}, 0.1 \%$ Triton X-100, $0.01 \mathrm{mg} \mathrm{ml}^{-1}$ aprotinin, $0.05 \mathrm{mg} \mathrm{ml}^{-1}$ PMSF), followed by sonication on ice and ultracentrifugation. Equal amounts of protein were electophoretically separated in $10-12 \%$ SDS polyacrylamide gels and proteins were immobilised by transfer onto nitrocellulose membranes. Membranes were immunoprobed with the relevant antibodies followed by a secondary, peroxidaselabelled antibody. The proteins of interest were visualized using a luminescent visualization system $\left(\mathrm{HRPL}^{\mathrm{TM}}\right.$, National Diagnostics, Hull, UK).

\section{Statistics}

All experiments were performed at least twice and results shown are means of all determinations unless otherwise stated. Statistical comparisons were made using an unpaired, two-tailed $t$-test or ANOVA followed by the Fisher PLSD test (StatView 4.0 software package for Apple Macintosh). All comparisons are made relative to an untreated control, unless otherwise stated, and significance is indicated as ${ }^{\star} P<0.05,{ }^{* *} P<0.01,{ }^{* *} P<0.005$.

\section{RESULTS}

\section{Loss of cell viability and induction of apoptosis}

We have previously shown that treatment of pancreatic adenocarcinoma cells with ATRA or 9cRA for 6 days results in a dosedependent reduction in the number of viable cells. We show here that 9cRA induced apoptosis in BxPc-3, T3M-4 and AsPc-1, but not A818-4 pancreatic adenocarcinoma cells (Figure 1).

\section{Suppression of apoptosis by Bcl-2}

All cells in our study expressed moderate levels of Bcl-2 (not shown). To assess if enhanced expression of this anti-apoptotic protein would affect the ability of 9cRA to induce apoptosis, 


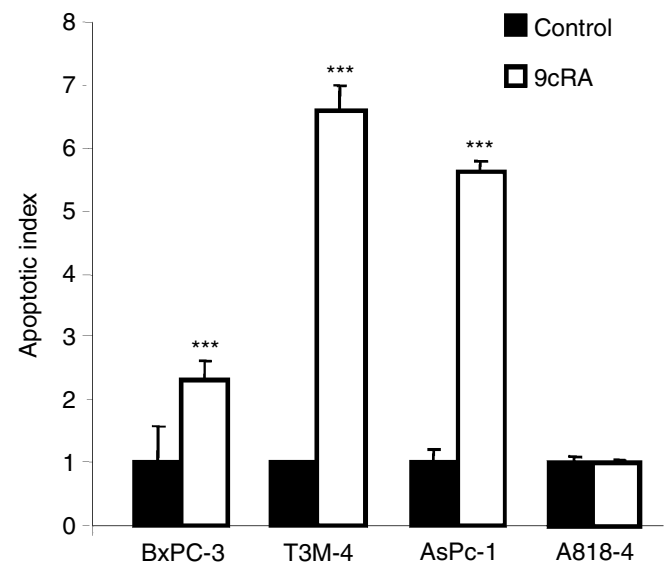

Figure I Assessment of apoptosis by cell death detection ELISA. The cells were treated with 500 nM 9cRA for 6 days and results are expressed as means \pm s.d. $(n=4)$.

T3M-4 cells were transfected with the pUSEamp.Bcl-2 plasmid. This resulted in generation of three clones that stably overexpressed Bcl-2 (Figure 2A). Two of these, clones 2 and 7, and the control transfected clone $\mathrm{C} 1$ were used in all subsequent experiments. We show that the apoptosis-inducing effect of 9cRA is suppressed by $\mathrm{Bcl}-2$, as clone 2 and 7 were significantly less sensitive than clone $\mathrm{C} 1$ or parental, untransfected T3M-4 cells. Following treatment with $500 \mathrm{~nm}$ 9cRA for 6 days, loss of cell viability, as determined using MTT, was decreased and no apoptosis could be detected (Figure 2B,C). Furthermore, expression levels of $\mathrm{Bcl}-2$ and $\mathrm{Bax}$ in parental T3M-4 cells were examined by semiquantitative Western blotting in untreated cells and on day 2 and 4 of treatment with $500 \mathrm{nM} 9 \mathrm{cRA}$. A decrease in the $\mathrm{Bcl}-2 / \mathrm{Bax}$ ratio was found in treated cells, and this was due to decreased levels of Bcl-2 as well as increased levels of Bax (Figure 3). 9cRA also caused a slight, non-significant decrease in the level of the anti-apoptotic Bcl-2 family member Mcl-1 (data not shown).

\section{Effects of caspase inhibition}

Cells were preincubated with the broad-range caspase inhibitors ZVAD.fmk or Boc-D.fmk for $3 \mathrm{~h}$ before addition of 9cRA. They were subsequently treated for up to 6 days and fresh medium, containing both compounds, was added every $48 \mathrm{~h}$. Addition of either of the inhibitors resulted in a significant decrease in nuclear fragmentation, as determined by Cell Death Detection ELISA on day 6. Interestingly, mitochondrial activity was not affected, and no increase in cell viability was seen at any time point (Figure 4).

\section{Receptor expression}

Expression of RAR- $\alpha, \beta$ and $\gamma$ and RXR- $\alpha$ was assessed in AsPc-1, BxPc-3, T3M-4 and A818-4 cells, using semi-quantitative Western blotting. Weak expression of RAR- $\alpha$ was detected in the four cell lines, whereas very weak expression of RAR- $\beta$ could be detected in T3M-4 only. RAR- $\gamma$ was expressed in AsPc-1, BxPc-3 and T3M-4 cells, but only very weakly in 9cRA-resistant A818-4 cells. Approximately equal levels of RXR-alpha were seen in all four cell lines (Figure 5). Using RT-PCR or Western blotting, we could detect no induction of receptor expression upon retinoid treatment (data not shown).

\section{Role of RAR and RXR subtypes in apoptosis}

To assess the role of receptor subtypes in retinoid-induced apoptosis in our cells, we treated T3M-4 and BxPc-3 with subtype

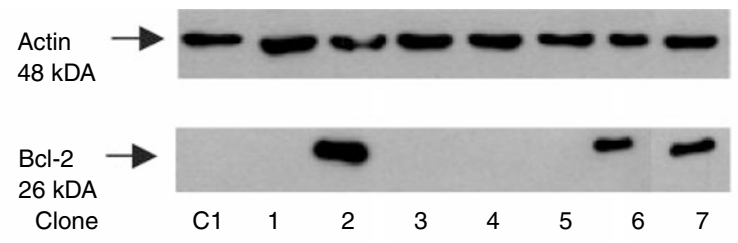

B

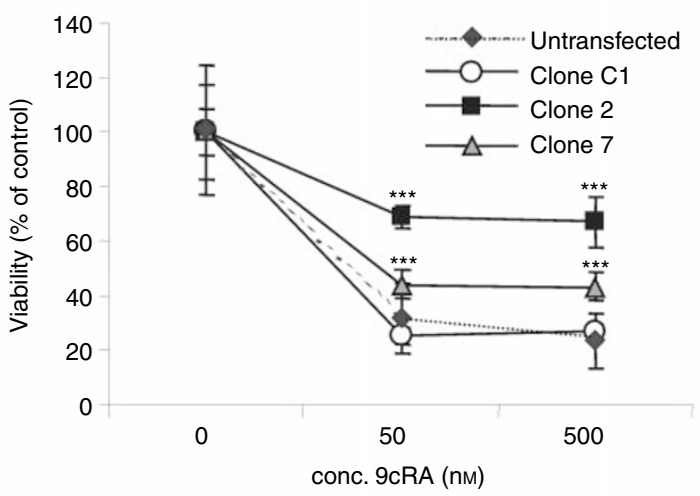

C

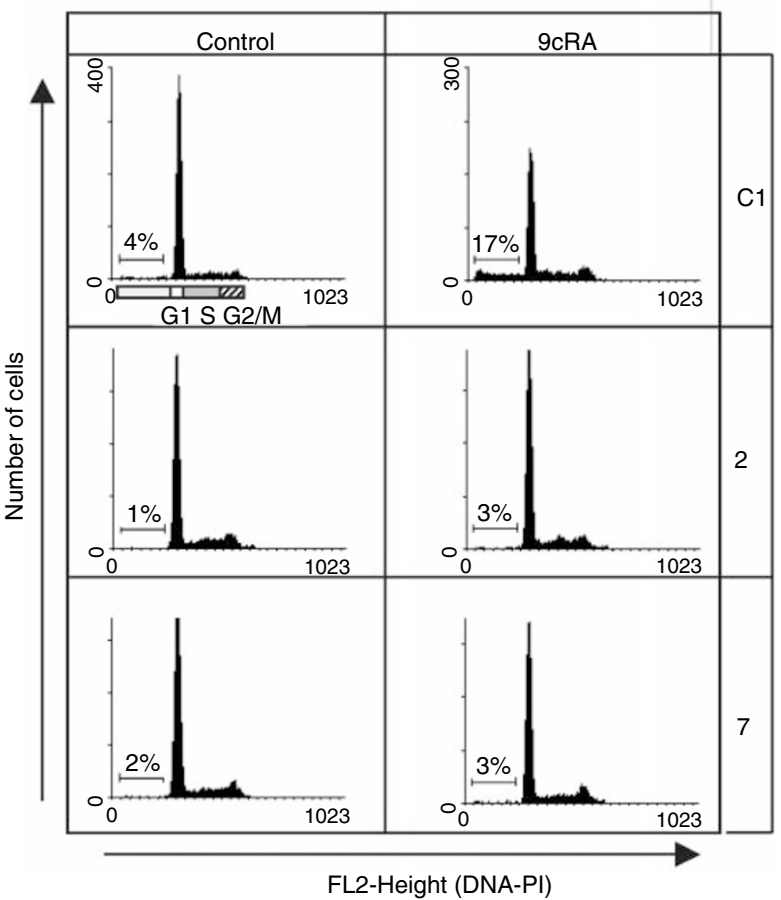

Figure 2 (A) Western analysis of $\mathrm{Bcl}-2$ expression in transfected T3M-4 cells. Clone $\mathrm{Cl}$ is transfected with the control vector. (B) The inhibitory effect of 9cRA is significantly suppressed in cells overexpressing Bcl-2. Viability was assessed on day 6 of treatment, using an MTT assay. Results are expressed as means \pm s.d. $(n=6)$. (C) Propidium iodide staining and cell cycle analysis confirm that apoptosis is inhibited. Representative histograms are shown and percentages are means of duplicate treatments. Cells were treated with 500 nM 9cRA for 6 days. 


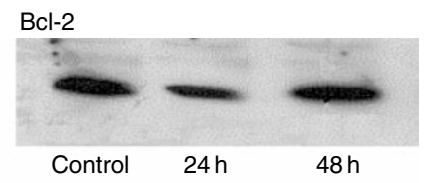

Bax
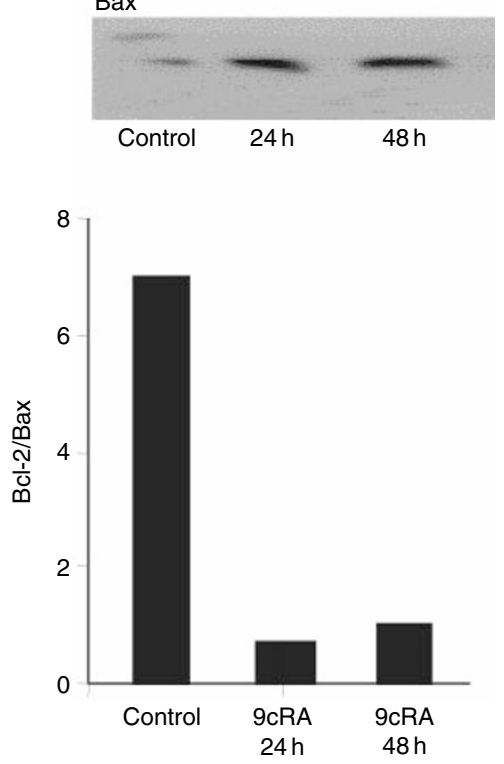

Figure 3 The $\mathrm{Bcl}-2 / \mathrm{Bax}$ ratio is decreased in parental T3M-4 cells after treatment with 500 nM 9cRA. Protein levels were assessed by semi-quantitative Western blotting and laser densitometry was used to quantify the signals. A representative blot is shown and the densitometric values are means of two determinations.

selective retinoids for up to 6 days. We show that only two of the compounds, the RAR- $\gamma$ selective LG101093 and the pan-RAR agonist LGD1550, caused reduced cell viability. As previously reported (Shalinsky et al, 1997), LGD1550 was significantly more potent than any of the other compounds, with an $\mathrm{IC}_{50}$ value which is around 500-fold lower than the $\mathrm{IC}_{50}$ value of LG101093. As single agents, the pan-RXR selective LG101305 and the RAR- $\alpha$ selective LG030593 had little or no effects (Figure 6). However, addition of LG101305 to LG101093 or LGD1550 resulted in significantly increased inhibition of cell viability (Figure 7A), although this was only observed at relatively low levels of LG101093 and LGD1550. Co-treatment with LG030593 plus LG101093 did not confer any additional inhibition, compared to LG101093 alone (not shown). Importantly, addition of an RAR-beta/gamma selective antagonist, LG030403, resulted in significant suppression of the effects of LGD1550 as well as 9cRA (Figure 7B)

Using the Cell Death Detection ELISA, it was confirmed that LG101093 and LGD1550 induce apoptosis in T3M-4 cells, causing significant nuclear fragmentation. Neither of the other compounds had this effect. Again, LGD1550 was significantly more potent, causing the same level of apoptosis as LG101093 and 9cRA at a 50 -fold lower concentration (Figure 8A,B). Addition of the RAR$\beta / \gamma$ antagonist, LG030403, resulted in significant suppression of the effects of LGD1550 as well as 9cRA (Figure 8B).

\section{DISCUSSION}

ATRA and 9cRA have previously been reported to have anti-proliferative effects and to modulate differentiation in pancreatic cancer cells (Rosewicz et al, 1995; Bold et al, 1996; Louvet et al, 1996). We have shown that they can also act as potent apoptosis-inducers
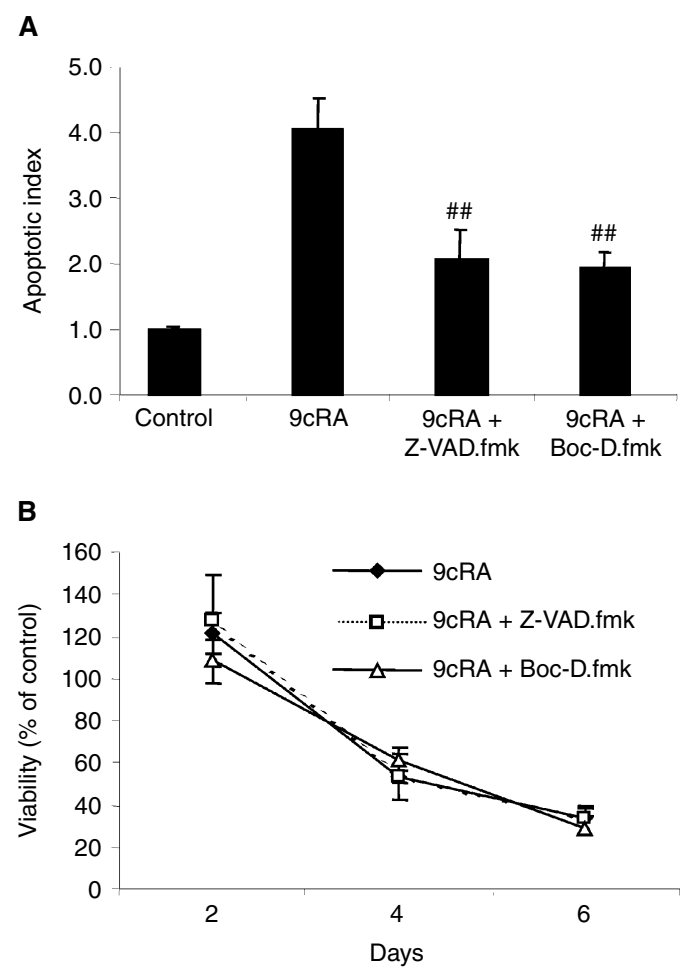

Figure 4 The broad-range caspase inhibitors Z-VAD.fmk and Boc-D.fmk specifically inhibited DNA fragmentation induced by 9 cRA $(\mathbf{A})$, but had no effect on mitochondrial activity (B). T3M-4 cells were treated with $500 \mathrm{nM}$ 9cRA $\pm 50 \mu \mathrm{M}$ Z-VAD.fmk or $25 \mu \mathrm{M}$ Boc-D.fmk for 6 days and DNA fragmentation and viability were assessed using the Cell Death Detection ELISA $(n=4)$ and an MTT assay $(n=6)$, respectively. \#\# Indicates a significant difference compared to 9cRA alone $(P<0.01)$.

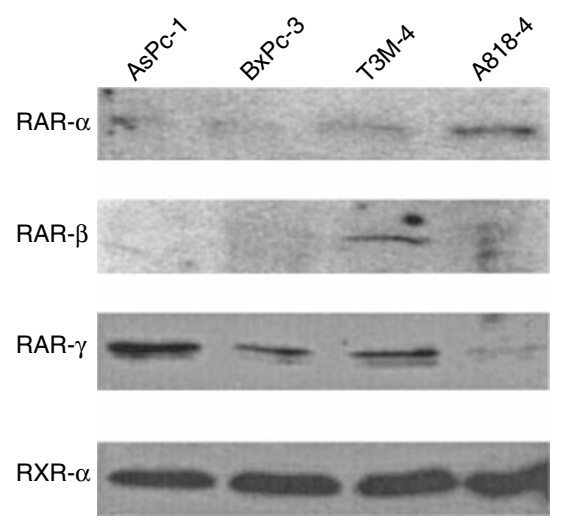

Figure 5 Semi-quantitative Western blots showing expression of RAR- $\alpha$ $-\beta$ and $-\gamma$ and RXR- $\alpha$ in AsPc- I, BxPc-3, T3M-4 and A8I8-4 pancreatic adenocarcinoma cell lines. Equal amounts of total protein was loaded on the gel, based on the Bradford assay.

(Pettersson et al, 2000), and in this study we have further elucidated the mechanisms behind this finding.

The Bcl-2 family of pro- and anti-apoptotic proteins plays an important role in apoptosis induced by a large variety of stimuli (Gross et al, 1999). We show here that overexpression of $\mathrm{Bcl}-2$ in T3M-4 cells efficiently inhibits induction of apoptosis by 9cRA. Treatment of parental T3M-4 cells with 9cRA also causes a decrease in the Bcl-2/Bax ratio, which may facilitate cell death. It may be hypothesised that this is important for the ability of retinoids to enhance the sensitivity of pancreatic cancer cells to other 


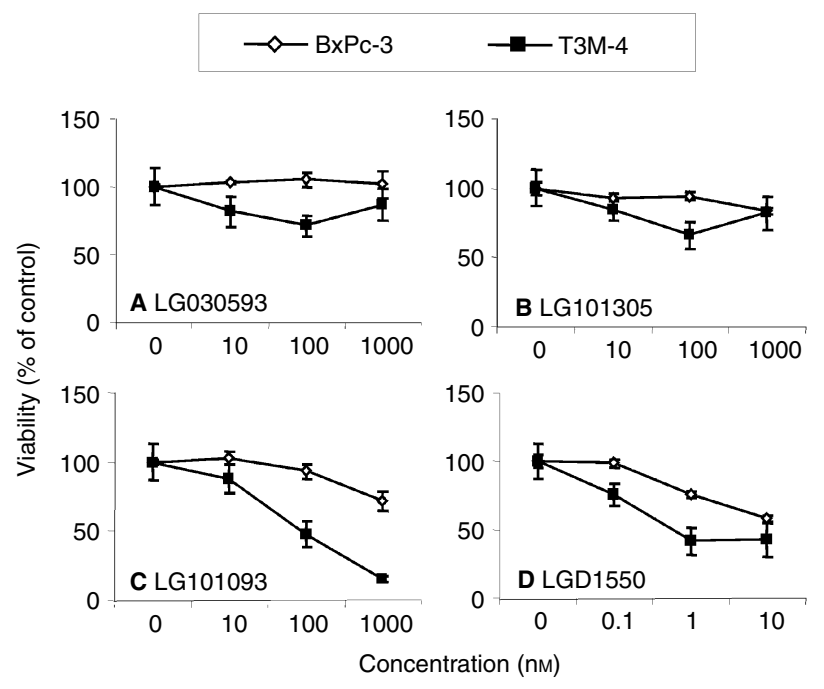

Figure 6 Reduced cell viability is seen in BxPc-3 and T3M-4 cells treated with the RAR-y selective agonist LGI0I093 (C) and the pan-RAR agonist LGD I 550 (D), but not with the RAR- $\alpha$ selective agonist LG030593 (A) or the pan-RXR selective agonist LGI0I305 (B). Per cent viable cells, compared to untreated control cells, was determined on day 6 using an MTT assay and results are expressed as means \pm s.d. $(n=6)$.

cytotoxic drugs (Pettersson et al, 2001). Until now, the relationship between apoptosis induced by retinoic acid and expression of $\mathrm{Bcl}-2$ has been explored mainly in leukaemic cells. In agreement with the results presented here, down-regulation of $\mathrm{Bcl}-2$ expression by retinoids has been observed in acute promyelocytic and myeloid leukaemic cells, and stable overexpression of Bcl-2 has been shown to confer resistance to apoptosis (Nagy et al, 1996; Bocchia et al, 1997; Bruel et al, 1997).

In recent years, several reports have also suggested that the subcellular localisation of $\mathrm{Bcl}-2$ may determine its function. For example, stable overexpression of $\mathrm{Bcl}-2$ targeted to the endoplasmatic reticulum (ER) is protective against apoptosis induced by radiation as well as serum starvation, but does not inhibit apoptosis induced by etoposide, whereas $\mathrm{Bcl}-2$ targeted to the outer mitochondrial membrane protects against all these stimuli (Annis et al, 2001; Rudner et al, 2001). Conversely, transient overexpression of $\mathrm{Bcl}-2$ targeted to mitochondria has been shown to have pro-apoptotic activity (Wang et al, 2001). In view of this, it would be of interest in the future to study the subcellular localisation of Bcl-2 in our stably transfected T3M-4 cells. However, based on the results shown here, we can conclude that the majority of Bcl-2 localises in a favourable way, as it effectively inhibits apoptosis induced by 9cRA.

Interestingly, the broad-range caspase inhibitors Z-VAD.fmk and Boc-D.fmk were shown to inhibit nuclear fragmentation associated with apoptosis induced by 9cRA and still had no effect on over-all cell viability, identified by mitochondrial activity. This suggests that caspase activation is involved in retinoid-induced apoptosis in pancreatic adenocarcinoma cells, but that other mechanisms can substitute for this activation and execute cell death. The subject of caspase-independent apoptosis has been reviewed by Borner and Monney (1999), and they point out that although inhibitors like Z-VAD.fmk effectively block cleavage of caspase substrates as well as nuclear fragmentation, morphological and mitochondrial changes still occur in most systems and the cells eventually die, possibly through activation of alternative proteases. The possibility that the effect of 9cRA would be delayed, although not inhibited, by addition of the caspase inhibitors was considered, but discarded as no effect on mitochondrial activity was seen at any time-point studied. It has been reported that retinoic acids can have direct effects on mitochondria, causing a fall in transmembrane potential,
A
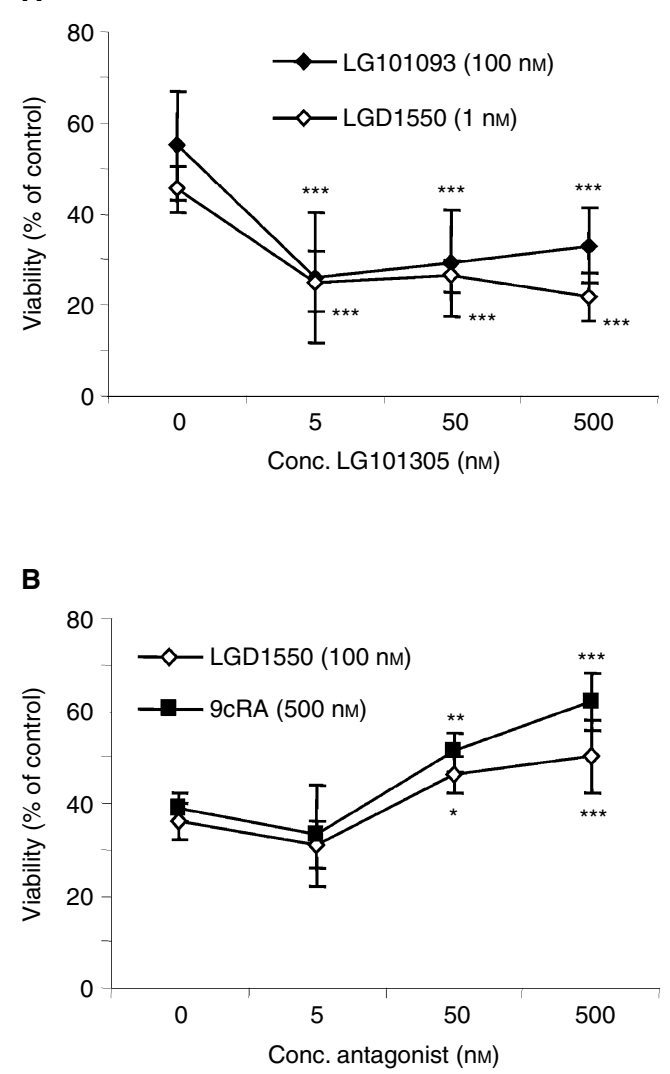

Figure 7 (A) Cotreatment with LGI01093+LGI01305 or LGDI550+LGI01305 results in enhanced loss of cell viability. T3M-4 ells were treated with LGI0I093 or LGDI550 plus increasing concentrations of LGI0I305 for 6 days and results are expressed as means \pm s.d. $(n=12)$. (B) The RAR- $\beta / \gamma$ selective antagonist LG030403 suppresses the inhibitory effect of LGDI550 and 9cRA in a dose-dependent manner. T3M-4 cells were treated with LGDI550 or 9cRA plus increasing concentrations of LG030403 for 6 days. Cell viability was determined using MTT and results are expressed as means \pm s.d. $(n=6)$. Per cent of control means relative to untreated cells.

organelle swelling and cytochrome $c$ release (Rigobello et al, 1999). These are interesting issues, which merit further investigation but are beyond the scope of this paper.

A major aim of this study was to investigate the role of different retinoid receptor subtypes in activation of the apoptotic response to the pan-agonist 9cRA. We determined that the four cell lines studied showed similar receptor expression patterns, with one important exception. That is, 9cRA-resistant A818-4 cells express almost undetectable levels of RAR- $\gamma$. RAR- $\alpha$, RAR- $\gamma$ and RXR- $\alpha$ were expressed in all cells but weak expression of RAR- $\beta$ could be detected in T3M-4 cells only. This is in agreement with previous reports, which have shown that RAR- $\beta$ expression is generally low or absent in pancreatic cancer cells (Kaiser et al, 1997). Although induction of RAR- $\beta$ has been reported to be an indicator of retinoid response (Seewaldt et al, 1995; Lee et al, 2000; Sun et al, 2000), we could detect no induction of either RAR subtype upon retinoid treatment. This may seem surprising, but is likely to be due to methylation of the RAR-beta gene (Ueki et al, 2000).

Among the receptor subtype selective compounds tested, only two had inhibitory activity as single agents. LG101093, which binds selectively to RAR- $\gamma$ and the pan RAR-agonist LGD1550 both caused significantly reduced cell viability and induced nuclear fragmentation, characteristic of apoptosis. Furthermore, an RAR- $\beta / \gamma$ selective antagonist (LG030403) was shown to counteract the effect 
A

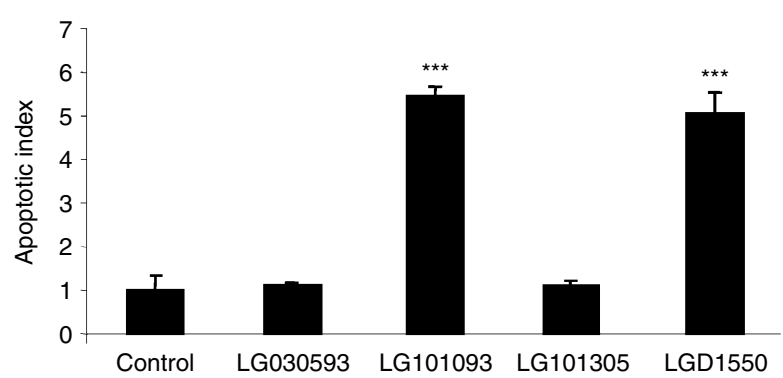

B

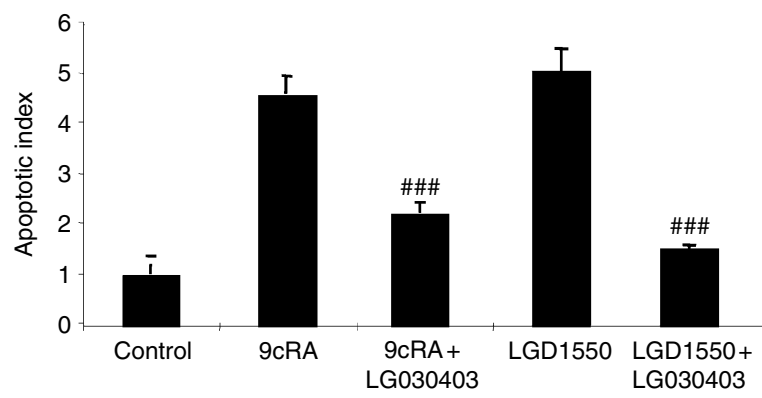

Figure 8 LGI0I093 and LGDI550 induce apoptosis in T3M-4 cells as determined by the Cell Death Detection ELISA. Cells were treated for 6 days with 10 nM of LGDI550 and 500 nM of each of the other compounds. (B) The RAR- $\beta / \gamma$ selective antagonist LG030403 inhibits apoptosis induced by 9 cRA and LGDI550. Cells were treated for 6 days with $500 \mathrm{nM} 9 \mathrm{cRA}$ or $10 \mathrm{nM}$ LGDI550, with or without $500 \mathrm{nM}$ LG030403. Results are means \pm s.d. $(n=4)$. \#\#\# Indicates a significant difference compared to agonist alone $(P<0.005)$.

of LG101093, LGD1550, as well as 9cRA. Taken together, these results demonstrate that activation of RAR- $\gamma$ is essential for induction of apoptosis by retinoids in pancreatic adenocarcinoma cells. This is also supported by the fact that A818-4 are resistant to the effects of 9cRA. A number of earlier studies have established a connection between RAR- $\gamma$ and retinoid induced growth arrest and apoptosis in various cell types. Expression of RAR- $\beta$ is often lost or decreased in tumour cells (Seewaldt et al, 1995; Wan et al, 1999; Lee et al, 2000; Sun et al, 2000). However, results from a study in melanoma cells showed that, although RAR- $\beta$ expression was induced by activation of any of the RAR or RXR subtypes, only RAR- $\gamma$ selective compounds were able to induce differentiation followed by apoptosis. This suggests a critical role for RAR$\gamma$ in apoptosis (Spanjaard et al, 1997). The same finding has been observed in neuroblastoma cells. In contrast to ATRA, which induces differentiation in these cells, RAR- $\gamma$ selective retinoids were shown to induce apoptotic cell death (Meister et al, 1998).

Pancreatic carcinomas, like many other tumours, show frequent loss of RAR- $\beta$ expression and an association between this loss and development of pancreatic malignancy is supported by transfection experiments restoring RAR- $\beta$ expression in pancreatic cancer cells (Kaiser et al, 1997). On the other hand, selective loss of RAR- $\gamma$ expression in retinoid resistant cells (see Figures 1 and 5 and Rosewicz et al, 1995) implies an important role for this subtype in conferring sensitivity to retinoids. Kaiser et al (1998) demonstrated that reintroduction of $\mathrm{RAR}-\gamma 1$ into resistant cells could restore their ability to be growth inhibited in response to retinoic acid treatment. Results presented in this study also make it clear that activation of RAR- $\gamma$ is necessary and sufficient for induction of apoptosis in human pancreatic cancer cells. Since the RXR agonist LG101305 alone had no effect on cell viability, RXR homodimers do not mediate the response. Instead, the fact that the effects of LG101093 and LGD1550 are potentiated by LG101305 supports a model where RAR/RXR heterodimers are optimally activated when both RAR and RXR bind their ligand (Apfel et al, 1995; Minucci et al, 1997). However, RXR activation is clearly not required, since this potentiation by LG101305 was abolished at higher concentrations of LG101093 and LGD1550.

In summary, retinoids activating RARs, and RAR- $\gamma$ in particular, induce apoptosis in pancreatic adenocarcinoma cells via a pathway involving altered expression of Bcl-2 family members as well as caspase activation. Together with our previous report that 9cRA enhances the effect of currently used chemotherapy (Pettersson et $a l, 2001)$, and promising clinical data from a phase II trial of 13 -cis retinoic acid and interferon- $\alpha$ (Brembeck et al, 1998), this encourages further work evaluating the use of receptor subtypeselective retinoids in management of this disease.

\section{ACKNOWLEDGEMENTS}

This work was funded by the Ralph Bates Pancreatic Research Fund.

\section{REFERENCES}

Allegretto EA, McClurg MR, Lazarchik SB, Clemm DL, Kerner SA, Elgort MG, Boehm MF, White SK, Pike JW, Heyman RA (1993) Transactivation properties of retinoic acid retinoid $\mathrm{X}$ receptors in mammalian cells and yeast. Correlation with hormone binding and effects of metabolism. J Biol Chem 268: $26625-26633$

Annis MG, Zamzami N, Zhu W, Penn LZ, Kroemer G, Leber B, Andrews DW (2001) Endoplasmic reticulum localized Bcl-2 prevents apoptosis when redistribution of cytochrome $c$ is a late event. Oncogene 20: 1939-1952

Apfel CM, Kamber M, Klaus M, Mohr P, Keidel S, LeMotte PK (1995) Enhancement of HL-60 differentiation by a new class of retinoids with selective activity on retinoid X receptor. J Biol Chem 270: 30765-30772

Bocchia M, Xu Q, Wesley U, Xu Y, Korontsvit T, Loganzo F, Albino AP, Scheinberg DA (1997) Modulation of p53, WAF1/p21 and BCL-2 expression during retinoic acid-induced differentiation of NB4 promyelocytic cells. Leuk Res 21: 439-447

Bold RJ, Ishizuka J, Townsend Jr CM, Thompson JC (1996) All-trans-retinoic acid inhibits growth of human pancreatic cancer cell lines. Pancreas 12: $189-195$

Bollag W, Majewski S, Jablonska S (1994) Cancer combination chemotherapy with retinoids: experimental rationale. Leukemia 8: 1453-1457

Borner C, Monney L (1999) Apoptosis without caspases: an inefficient molecular guillotine? Cell Death Differ 6: 497-507

Brembeck FH, Schoppmeyer K, Leupold U, Gornistu C, Keim V, Mossner J, Riecken EO, Rosewicz S (1998) A phase II pilot trial of 13-cis retinoic acid and interferon-alpha in patients with advanced pancreatic carcinoma. Cancer 83: 2317-2323

Bruel A, Karsenty E, Schmid M, McDonnell TJ, Lanotte M (1997) Altered sensitivity to retinoid-induced apoptosis associated with changes in the subcellular distribution of Bcl-2. Exp Cell Res 233: 281-287

De Luca LM, Darwiche N, Jones CS, Scita G (1995) Retinoids in differentiation and neoplasia. Sci Am Sci Med 2: 28-37

Evans RM (1988) The steroid and thyroid hormone receptor superfamily. Science 240: $889-895$

Freedman LP (1999) Increasing the complexity of coactivation in nuclear receptor signaling. Cell 97: 5-8

Glass CK, Rosenfeld MG (2000) The coregulator exchange in transcriptional functions of nuclear receptors. Genes Dev 14: $121-141$

Gross A, McDonnell JM, Korsmeyer SJ (1999) BCL-2 family members and the mitochondria in apoptosis. Genes Dev 13: 1899-1911 
Harris J, Bruckner H (2001) Adjuvant and neoadjuvant therapies of pancreatic cancer: a review. Int J Pancreatol 29: 1-7

Heyman RA, Mangelsdorf DJ, Dyck JA, Stein RB, Eichele G, Evans RM, Thaller C (1992) 9-cis retinoic acid is a high affinity ligand for the retinoid X receptor. Cell 68: $397-406$

Kaiser A, Herbst H, Fisher G, Koeningsmann M, Berdel WE, Riecken EO, Rosewicz S (1997) Retinoic acid receptor b regulates growth and differentiation in human pancreatic carcinoma cells. Gastroenterology 113: $920-$ 929

Kaiser A, Wolf-Breitinger M, Albers A, Dorbic T, Wittig B, Riecken EO, Rosewicz S (1998) Retinoic acid receptor gammal expression determines retinoid sensitivity in pancreatic carcinoma cells. Gastroenterology 115: 967-977

Lee MO, Han SY, Jiang S, Park JH, Kim SJ (2000) Differential effects of retinoic acid on growth and apoptosis in human colon cancer cell lines associated with the induction of retinoic acid receptor beta. Biochem Pharmacol 59: $485-496$

Lippman SC, Heyman RA, Kurie JM, Benner SE, Hong WK (1995) Retinoids and chemoprevention: clinical and basic studies. J Cell Biochem Suppl 22: $1-10$

Louvet C, Djelloul S, Forgue-Lafitte ME, Mester J, Zimber A, Gespach C (1996) Antiproliferative effects of the arotinoid Ro 40-8757 in human gastrointestinal and pancreatic cancer cell lines: combination with 5-fluoruracil and interferon-a. Br J Cancer 74: 394-399

Meister B, Fink FM, Hittmair A, Marth C, Widschwendter M (1998) Antiproliferative activity and apoptosis induced by retinoic acid receptorgamma selectively binding retinoids in neuroblastoma. Anticancer Res 18: $1777-1786$

Minucci S, Leid M, Toyama R, Saint-Jeannet J-P, Peterson VJ, Horn V, Ishmael JE, Bhattacharyya N, Dey A, Dawid IB, Ozato K (1997) Retinoid $\mathrm{X}$ receptor (RXR) within the RXR-retinoic acid receptor heterodimer binds its ligand and enhances retinoid-dependent gene expression. Mol Cell Biol 17: $644-655$

Mosmann T (1983) Rapid colorimetric assay for cellular growth and survival: application to proliferation and cytotoxicity assays. J Immunol Methods 65: $55-64$

Nagy L, Thomazy VA, Chandraratna RA, Heyman RA, Davies PJ (1996) Retinoid-regulated expression of BCL-2 and tissue transglutaminase during the differention and apoptosis of human myeloid leukemia (HL-60) cells. Leuk Res 20: $499-505$

Napoli JL (1996) Biochemical pathways of retinoid transport, metabolism, and signal transduction. Clin Immunol Immunopathol 80: S52 - S62

Pettersson F, Colston KW, Dalgleish AG (2000) Differential and antagonistic effects of 9-cis-retinoic acid and vitamin $\mathrm{D}$ analogues on pancreatic cancer cells in vitro. $\mathrm{Br} J$ Cancer 83: $239-245$

Pettersson F, Colston KW, Dalgleish AG (2001) Retinoic acid enhances the cytotoxic effects of gemcitabine and cisplatin in pancreatic adenocarcinoma cells. Pancreas 23: $273-279$

Rigobello MP, Scutari G, Friso A, Barzon E, Artusi S, Bindoli A (1999) Mitochondrial permeability transition and release of cytochrome $c$ induced by retinoic acids. Biochem Pharmacol 58: 665-670
Rios G, Conrad A, Cole D, Adams D, Leveen M, O’Brien P, Baron P (1999) Trends in indications and outcomes in the Whipple procedure over a 40year period. Am Surg 65: 889-893

Rosewicz S, Stier U, Brembeck F, Wiedenmann B, Riecken EO (1995) Retinoids: effect on growth, differentiation and nuclear receptor expression in human pancreatic carcinoma cell lines. Gastroenterology 109: $1646-$ 1660

Rosewicz S, Wiedenmann B (1997) Pancreatic carcinoma. Lancet 349: 485 489

Rudner J, Lepple-Wienhues A, Budach W, Berschauer J, Friedrich B, Wesselborg S, Schulze-Osthoff K, Belka C (2001) Wild-type, mitochondrial and ER-restricted Bcl-2 inhibit DNA damage-induced apoptosis but do not affect death receptor-induced apoptosis. J Cell Sci 114: 4161-4172

Saffiotti U, Montesano R, Sellakumar AR, Borg SA (1967) Experimental cancer of the lung. Inhibition of vitamin A of the induction of tracheobronchial squamous metaplasia and squamous cell tumours. Cancer 20: $857-864$

Seewaldt VL, Johnson BS, Parker MB, Collins SJ, Swisshelm K (1995) Expression of retinoic acid receptor beta mediates retinoic acid-induced growth arrest and apoptosis in breast cancer cells. Cell Growth Differ 6: 1077-1088

Shalinsky DR, Bischoff ED, Lamph WW, Zhang L, Boehm MF, Davies PJ, Nadzan AM, Heyman RA (1997) A novel retinoic acid receptor-selective retinoid, ALRT1550, has potent antitumor activity against human oral squamous carcinoma xenografts in nude mice. Cancer Res 57: 162-168

Spanjaard RA, Ikeda M, Lee PJ, Charpentier B, Chin WW, Eberlein TJ (1997) Specific activation of retinoic acid receptors (RARs) and retinoid X receptors reveals a unique role for RARgamma in induction of differentiation and apoptosis of S91 melanoma cells. J Biol Chem 272: 18990-18999

Sun SY, Wan H, Yue P, Hong WK, Lotan R (2000) Evidence that retinoic acid receptor beta induction by retinoids is important for tumor cell growth inhibition. J Biol Chem 275: 17149-17153

Ueki T, Toyota M, Sohn T, Yeo CJ, Issa JP, Hruban RH, Goggins M (2000) Hypermethylation of multiple genes in pancreatic adenocarcinoma. Cancer Res 60: $1835-1839$

van Riel JM, van Groeningen CJ, Pinedo HM, Giaccone G (1999) Current chemotherapeutic possibilities in pancreaticobiliary cancer. Ann Oncol 10(Suppl 4): $157-161$

Vieira AV, Schneider WJ, Vieira PM (1995) Retinoids: transport, metabolism and mechanisms of action. J Endocrinol 146: 201-207

Wagner M, Dikopoulos N, Kulli C, Friess H, Buchler MW (1999) Standard surgical treatment in pancreatic cancer. Ann Oncol 10:(Suppl 4): 247-251

Wan H, Oridate N, Lotan D, Hong WK, Lotan R (1999) Overexpression of retinoic acid receptor beta in head and neck squamous cell carcinoma cells increases their sensitivity to retinoid-induced suppression of squamous differentiation by retinoids. Cancer Res 59: $3518-3526$

Wang NS, Unkila MT, Reineks EZ, Distelhorst CW (2001) Transient expression of wild-type or mitochondrially targeted Bcl-2 induces apoptosis, whereas transient expression of endoplasmic reticulum-targeted Bcl-2 is protective against Bax-induced cell death. J Biol Chem 276: 44117-44128 